\title{
Optimization of enrichment levels of vitamin D in Ice cream
}

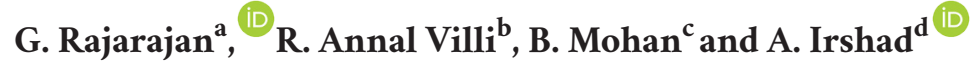 \\ ${ }^{a}$ Assistant Professor, Department of Livestock Products Technology, Veterinary College and Research Institute, \\ Orathanadu-614 625, Tamil Nadu, TANUVAS. \\ bProfessor and Head, Department of Food Processing Technology, College of Food and Dairy Technology, Alamathy- \\ Koduvalli, Chennai - 600052 \\ 'Dean, Veterinary College and Research Institute, Namakkal-637 002, Tamil Nadu, TANUVAS. \\ dAssistant Professor, Meat Technology Unit, and Department of Livestock Products Technology, College of Veterinary \\ and Animal Sciences, Mannuthy-680 651
}

Corresponding author: G. Rajarajan | email: rajarajanvet@gmail.com

Co-authors: RAV: annalvilli@gmail.com ; BM: mohan.b@tanuvas.ac.in ; IA: irshad@kvasu.ac.in

Received: 29-08-2020, Accepted: 15-09-2020, Published online: 26-09-2020

\begin{abstract}
The study was conducted to optimize the level of enrichment of vitamin D in ice cream to rectify the deficiency. Vitamin D3 in the form of emulsion enriched at three different levels viz.1000IU, 1500IU and 2000IU in one litre of ice cream mix. The developed product was subjected to sensory evaluation for its acceptance using 9-point hedonic scale. Further, mechanical way of analyzing the attributes with the help of texture profile analyzer was carried out. The retention percentage of enriched vitamin D was carried out by high performance liquid chromatography. Hence it was concluded that vitamin D at $1500 \mathrm{IU} / \mathrm{L}$ could be enriched in ice cream mix to counteract vitamin D deficiency at large in general public.
\end{abstract}

Keywords: Vitamin D3, Ice cream, enrichment, Sensory Evaluation, Ice cream Texture, Fortification

\begin{abstract}
doi: https://doi.org/10.51128/jfas.2020.A005 | How to cite this article: Rajarajan, G., Villi, R.A., Mohan, B. and Irshad, A. 2020. Optimization of enrichment levels of vitamin D in Ice cream. Journal of Food and Animal Sciences, 01(01): 28-32.

Copyright: Rajarajan et al. Open Access. This article is distributed under the terms of the Creative Commons Attribution 4.0 International License (http://creativecommons.org/licenses/by/4.0/), which permits unrestricted use, distribution, and reproduction in any medium, provided you give appropriate credit to the original author(s) and the source, provide a link to the Creative Commons license, and indicate if changes were made. The Creative Commons Public Domain Dedication waiver (http://creativecommons.org/publicdomain/zero/1.0/) applies to the data made available in this article, unless otherwise stated.
\end{abstract}




\section{Introduction}

Vitamin D (also referred to as "calciferol")) plays an important role in maintaining a healthy mineralized skeletal system for most land vertebrates including humans. Animals and humans get vitamin D through food and by exposure to sunlight. Exposure to sunlight leads the photo production of vitamin $\mathrm{D}$, in the skin. Once synthesized, vitamin D3 is metabolized sequentially in the liver and kidney of the human and animal body to 1,25-dihydroxyvitamin D. The biological function of 1,25-dihydroxyvitamin $\mathrm{D}$ is to maintain the serum calcium and phosphorus concentrations within the normal range to sustain essential cellular functions and to promote mineralization of the skeleton (Holick, 1996).

Vitamin D not only plays an important role in maintaining mineralized skeletal system, but also act as an immunomodulatory hormone (Priet et al., 2013; Holick, 2007). Various studies showed that vitamin D has significant effect on both the innate and adaptive immune systems. Animal studies clearly reveled that the incorporation of optimum quantity of vitamin $\mathrm{D}$ or its metabolites in the regular diet leads to the less occurrence and progression of various immune-related diseases (Aranow, 2011). Most of our regular diet do not contain required level of vitamin D. Foods fortified with vitamin D have a variable amount present and cannot be depended on as a sole source of vitamin D nutrition. Exposure to sunlight provides most humans with their vitamin $\mathrm{D}$ requirement. Aging, sunscreen use and the change in the zenith angle of the sun can dramatically affect the cutaneous production of vitamin D. Vitamin D insufficiency and vitamin D deficiency is now being recognized as a major cause of metabolic bone disease in the elderly. Vitamin D deficiency not only causes osteomalacia but can exacerbate osteoporosis. Arora et al. (2014) reported that food fortification is thought to be a highly effective solution and among the most cost-effective public health interventions currently available. Thus present study was conducted to enrich vitamin $\mathrm{D}$ in ice cream which is relished by all age groups.

\section{Materials and Methods}

Vitamin $\mathrm{D}_{3}$ in an emulsified form, Vitex $\mathrm{D}$ $(205,000 \mathrm{IU} / \mathrm{mL})$ was used for enrichment in ice cream. Two milliliters of the emulsified vitamin D were blended in $2 \mathrm{~mL}$ of butter oil to obtain a final concentration of 100,000 IU/mL (Kazmi et al., 2007). Emulsion vitamin $\mathrm{D}_{3}$ was added at three different levels namely, 1000IU, 1500IU and 2000IU in one litre of ice cream mix before homogenization. The vitamin $\mathrm{D}_{3}$ enriched ice creams were subjected to sensory evaluation by a panel of seven members using 9 point hedonic scale (Singh et al., 2014). Then the enriched product was also subjected to texture profile analysis according to Chansathirapanich et al. (2016). The analysis was performed at $15^{\circ} \mathrm{C}$ using a TA.XT plus Texture Analyzer (Stable Micro System, United Kingdom). The enriched vitaminD $\mathrm{D}_{3}$ in ice cream was estimated by high performance liquid chromatography to assess the retention (Kazmi et al., 2007). All the statistical analyses were performed by using SPSS. Results were expressed as the mean \pm S.E., and in all applications (ANOVA) the differences were considered statistically significant at $\mathrm{P}<0.05$ and highly significant at $\mathrm{P}<0.01$.

\section{Results and Discussion}

The developed emulsion vitamin $\mathrm{D}_{3}$ enriched Ice cream was assessed by sensory evaluation using 9-point hedonic scale by a panel of semi trained seven members and the scores were presented in Table- 1 and Figure - 1 .

The statistical analysis revealed that $\mathrm{T}_{2}$ showed better sensory scores than $\mathrm{T}_{1}$ and $\mathrm{T}_{3}$ and hence emulsion vitamin $\mathrm{D}_{3}$ at $1500 \mathrm{IU}$ per litre ice cream mix may be incorporated for enrichment in ice cream. The enriched ice cream samples were also subjected to texture profile analysis and the results were presented in Table- 2 and the results revealed that $\mathrm{T}_{2}$ was comparable with that of control than $\mathrm{T}_{1}$ and $\mathrm{T}_{3}$. The retention of emulsion vitamin $\mathrm{D}_{3}$ in enriched ice cream was assessed by high performance liquid chromatography and the results were presented in Table-3. The $\mathrm{T}_{2}$ had better retention than $\mathrm{T}_{1}$ and $\mathrm{T}_{3}$ and hence emulsion vitamin $\mathrm{D}_{3}$ could be incorporated at $1500 \mathrm{IU}$ per litre ice cream mix for enrichment in ice cream. The findings were in accordance with Kazmi et al. (2007) and Leskauskaite et al. (2016).

\section{Conclusions}

Vitamin D deficiency with its multifarious effects on health status, levies a huge burden on the healthcare system worldwide. Several advanced nations have launched nationwide fortification programs to improve vitamin D status. India must follow suit. Foods are rarely fortified with vitamin D in India. Hence an attempt has been made to enrich emulsion vitamin $\mathrm{D}_{3}$ in ice cream at $1500 \mathrm{IU}$ per litre of mix which evinced better overall sensory acceptability, texture profile and retention in the finished product. Therefore it might 
Table 1: Enrichment of emulsion vitamin $\mathrm{D}_{3}$ in Ice cream assessed by sensory evaluation using 9-point hedonic scale $\left(\right.$ Mean \pm SE) ${ }^{*}$

\begin{tabular}{|l|c|c|c|c|}
\hline \multicolumn{1}{|c|}{ Sensory attributes } & Control & $\mathbf{T}_{1}$ & $\mathbf{T}_{2}$ & $\mathbf{T}_{3}$ \\
\hline Flavour & $8.625 \pm 0.078^{\mathrm{b}}$ & $8.525 \pm 0.080^{\mathrm{b}}$ & $8.550 \pm 0.080^{\mathrm{a}}$ & $8.425 \pm 0.101^{\mathrm{a}}$ \\
\hline Body \& Texture & $8.500 \pm 0.087^{\mathrm{c}}$ & $8.350 \pm 0.105^{\mathrm{bc}}$ & $8.425 \pm 0.087^{\mathrm{b}}$ & $8.300 \pm 0.114^{\mathrm{a}}$ \\
\hline Colour \& Appearance & $8.100 \pm 0.112$ & $8.025 \pm 0.104$ & $8.100 \pm 0.112$ & $8.025 \pm 0.098$ \\
\hline Melting quality & $8.400 \pm 0.106$ & $8.325 \pm 0.110$ & $8.375 \pm 0.111$ & $8.225 \pm 0.121$ \\
\hline Overall acceptability & $8.600 \pm 0.093^{\mathrm{c}}$ & $8.510 \pm 0.095^{\mathrm{c}}$ & $8.525 \pm 0.095^{\mathrm{b}}$ & $8.450 \pm 0.094^{\mathrm{a}}$ \\
\hline
\end{tabular}

${ }^{*}$ Mean \pm SE with different superscripts in a row differ significantly $(\mathrm{P}<0.05)$.

C- Control (unfortified); $\quad \mathrm{T}_{1}$ - Treatment with $1000 \mathrm{IU} / \mathrm{L}$ Vit.D

$\mathrm{T}_{2}$ - Treatment with 1500 IU/L Vit.D ${ }_{3 ;} \mathrm{T}_{3}$ - Treatment with $2000 \mathrm{IU} / \mathrm{L}$ Vit.D

$\mathrm{n}=42$ for each treatment

Sensory scores based on 9-point hedonic scale, where 1: dislike extremely and 9: like extremely

Table 2: Enrichment of emulsion vitamin $\mathrm{D}_{3}$ in Ice cream assessed by texture analysis (Mean $\left.\pm \mathrm{SE}\right)^{\#}$

\begin{tabular}{|l|c|r|r|r|}
\hline \multicolumn{1}{|c|}{ Texture parameters } & Control & \multicolumn{1}{c|}{$\mathbf{T}_{1}$} & $\mathbf{T}_{2}$ & $\mathbf{T}_{3}$ \\
\hline Firmness $(\mathrm{g})$ & $31.372 \pm 0.389^{\mathrm{a}}$ & $29.605 \pm 0.356^{\mathrm{b}}$ & $30.689 \pm 0.371^{\mathrm{c}}$ & $28.637 \pm 2.114^{\mathrm{c}}$ \\
\hline Consistency (g/sec) & $510.603 \pm 21.134^{\mathrm{c}}$ & $489.280 \pm 18.614^{\mathrm{c}}$ & $506.005 \pm 21.753^{\mathrm{ab}}$ & $499.356 \pm 27.401^{\mathrm{a}}$ \\
\hline Cohesiveness (g) & $-14.925 \pm 1.153^{\mathrm{b}}$ & $-12.524 \pm 1.127^{\mathrm{c}}$ & $-13.504 \pm 1.461^{\mathrm{a}}$ & $-13.517 \pm 0.642^{\mathrm{a}}$ \\
\hline $\begin{array}{l}\text { Viscosity index }(\mathrm{g} / \\
\text { sec) }\end{array}$ & $2.368 \pm 0.823^{\mathrm{a}}$ & $1.915 \pm 0.644^{\mathrm{ab}}$ & $2.311 \pm 1.357^{\mathrm{b}}$ & $2.779 \pm 0.524^{\mathrm{b}}$ \\
\hline
\end{tabular}

${ }^{\#}$ Mean \pm SE with different superscripts in a row differ significantly $(\mathrm{P}<0.05)$.

C- Control (unfortified); $\quad \mathrm{T}_{1}$ - Treatment with $1000 \mathrm{IU} / \mathrm{L}$ Vit. $\mathrm{D}_{3 ;}$

$\mathrm{T}_{2}$ - Treatment with 1500 IU/L Vit.D ${ }_{3 ;} \mathrm{T}_{3}$ - Treatment with 2000 IU/L Vit.D

$\mathrm{n}=6$ for each treatment

be concluded that vitamin $\mathrm{D}_{3}$ enriched ice cream could be a public health intervention to address vitamin $\mathrm{D}$ deficiency.

\section{Authorship contribution statement}

G. Rajarajan: Conceptualization, Methodology, Formal analysis, Investigation, Writing - original draft, Writing - review \& editing, R. Annal Villi: Conceptualization, Methodology, Writing - review \& editing. B. Mohan: Conceptualization, Methodology,
Writing - original draft, Writing - review \& editing. Irshad A: Conceptualization, Methodology, Writing original draft, Writing - review \& editing.

\section{Acknowledgments}

All the authors acknowledge and thank their respective Institutes and Universities.

\section{Funding}

No specific funding for the reserch work other than the $\mathrm{PhD}$ research grand from Tamil Nadu Veterinary 
Table 3: Retention of vitamin $\mathrm{D}_{3}$ in Ice cream enriched with emulsion vitamin $\mathrm{D}_{3}$ by high performance liquid chromatography

\begin{tabular}{|c|c|c|c|c|}
\hline Parameters & Control & $\mathbf{T}_{1}$ & $\mathbf{T}_{2}$ & $\mathbf{T}_{3}$ \\
\hline $\begin{array}{c}\text { Quantity of vitamin } \mathrm{D}_{3} \mathrm{re}- \\
\text { tained in ice cream }\end{array}$ & $9.154 \pm 0.303$ & $902.583 \pm 7.721$ & $1402.838 \pm 5.601$ & $1784.101 \pm 9.430$ \\
\hline Retention percentage (\%) & & 90.26 & 93.52 & 89.21 \\
\hline
\end{tabular}

${ }^{\#}$ Mean \pm SE with different superscripts in a row differ significantly $(\mathrm{P}<0.05)$.

C- Control (unfortified); $\quad \mathrm{T}_{1}$ - Treatment with $1000 \mathrm{IU} / \mathrm{L}$ Vit.D

$\mathrm{T}_{2}$ - Treatment with $1500 \mathrm{IU} / \mathrm{L}$ Vit.D $\mathrm{D}_{3 ;} \mathrm{T}_{3}$ - Treatment with $2000 \mathrm{IU} / \mathrm{L}$ Vit.D $\mathrm{D}_{3}$

$\mathrm{n}=6$ for each treatment

Figure 1: Enrichment of emulsion vitamin $\mathrm{D}_{3}$ in Ice cream assessed by sensory evaluation using 9-point hedonic scale $(\text { Mean } \pm \mathrm{SE})^{*}$

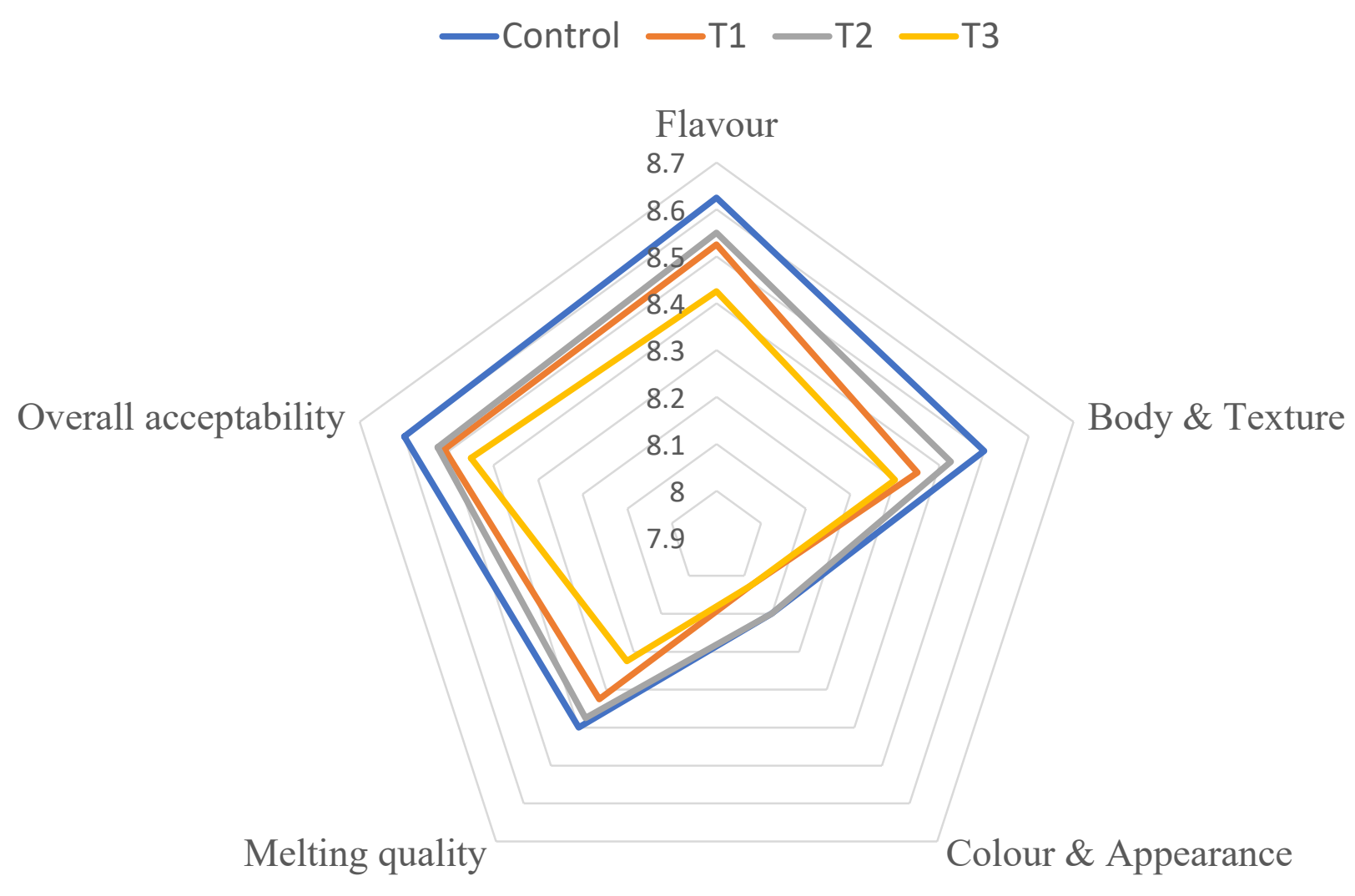


and Animal Sciences University.

\section{Declaration of Competing Interest}

All authors declare that there exist no commercial or financial relationships that could, in any way, lead to a potential conflict of interest.

\section{Reference}

Aranow, C. 2011. Vitamin D and the immune system. J. Investig. Med. 59:881-886. doi: 10.2310/ JIM.0b013e31821b8755

Arora, S., Shree, S. and Gupta, C. 2014. Fortification of milk and milk products for value addition. In: Dairy Year Book (2014-15), Sadana Publishers \& Distributors Palika Bazar, G.T. Road Ghaziabad-201001 (India) pp.105-109.

Chansathirapanich, W., Ngamchuachit, P. and Tansawat, R. 2016. Effect of fat content on characteristics of ice cream fortified with calcium and vitamin D3. Thai Journal of Pharmaceutical Sciences. 40 (3): 132-138.

Holick, M. F. 1996. Vitamin D and bone health. J. Nutr., 126(4):1159S-1164S.

Holick, M.F. 2007. Vitamin D deficiency. N. Engl.J. Med. 357:266-281. doi: 10.1056/NEJMra070553.

Kazmi, S.A., Vieth, R. and Rousseau, D. 2007. Vitamin D3 fortification and quantification in processed dairy products. Int. Dairy J., 17: 753-759.

Leskauskaite, D., Jasutiene, I., Malinauskyte, E., Kersiene, M. and Matusevicius, P. 2016. Fortification of dairy products with vitamin D3. Int. J. Dairy Technol., 69: 177-183.

Priet, B., Treiber, G., Pieber, T.R. and Amrein, K. 2013. Vitamin D and immune function. Nutrients. 5:2502-2521. doi: 10.3390/nu5072502.

Singh, A, Bajwa, U. and Goraya, R.K. 2014. Effect of storage period on the physicochemical, sensory and microbiological quality of bakery flavoured ice cream. Int. Journal of Engineering Research and Applications. 4(8): 80-90. 